\title{
Advanced Concept for Participation of Large Wind Farms in Ancillary Services
}

\author{
Ahmad-Rami Al-Awaad ${ }^{1}$ \\ ${ }^{1}$ KEMA Consulting GmbH \\ Kurt-Schumacher-Strasse 8, 53113 Bonn (Germany) \\ Phone/Fax number: 0049228 4469039/0049 228 4469099, e-mail: AhmadRami.AlAwaad @ kema.com
}

\begin{abstract}
The use of renewable energies is steadily growing. Wind energy is the main installed type of renewable energy in Germany. Wind power plants are concentrated in large wind farms. These wind farms are connected to high voltage grids. Despite the high level of installed wind power, wind farms have not contributed to voltage and frequency control (primary, secondary and tertiary control) until now. Wind farm owners receive a fixed payment from the transmission system operator for the energy they generate. This payment is much higher than the average variable costs of conventional power plants. This study shows that modern wind power plants and farms can also support voltage and frequency control. Wind farm owners receive more income through participating in frequency control than from the fixed payment for energy generated. This extra income can help to reduce the fixed payment for energy generated by wind farms.
\end{abstract}

\section{Keywords}

wind energy, ancillary services, frequency control, voltage control

\section{Introduction}

Today renewable energy plays an important role in energy supply. In some fields the development is still growing, especially for wind energy. It is expected that installed wind power in Germany will reach up to $60 \%$ of the German total load by the end of the year 2020 [1].

In Germany, renewable energies are promoted by a governmental act (Renewable Energy Sources Act; EEG) [2]. According to the EEG, wind power plant owners have feed-in priority into the grid, where the transmission system operator (TSO) must take over the energy. The TSO has to pay a fixed payment ( $87 € / \mathrm{MWh}$ ) for the energy generated by wind power plants. This payment is much higher than the average variable costs of conventional power plants.

Wind power plants are connected to the grid in wind farms. The installed power of a modern wind farm is large, particularly off-shore wind farms. Therefore, modern wind farms are connected to the high voltage grids [1]. These large wind farms have not participated in voltage and frequency control until now. They must not be separated from the grid either. Fig. 1 shows that the installed wind power in Germany up to the end of the year 2020 is larger than the load $\left(\mathrm{P}_{\mathrm{L}}\right)$ in the morning on a weekday in summer or approximately equal to the load in the night of a weekday in winter. Thus, in the case of high feed-in from wind power plants, conventional power plants must be partially disconnected from the grid, so that their contribution to voltage and frequency control is no longer available. This can then endanger the reliability of supply. Therefore, wind power plants must take over new tasks like supporting voltage and frequency control. This study investigated the participation of wind power plants and wind farms in voltage and frequency control (technical evaluation), as well as the economical benefits gained through the participation of wind power plants in frequency control (economical evaluation).

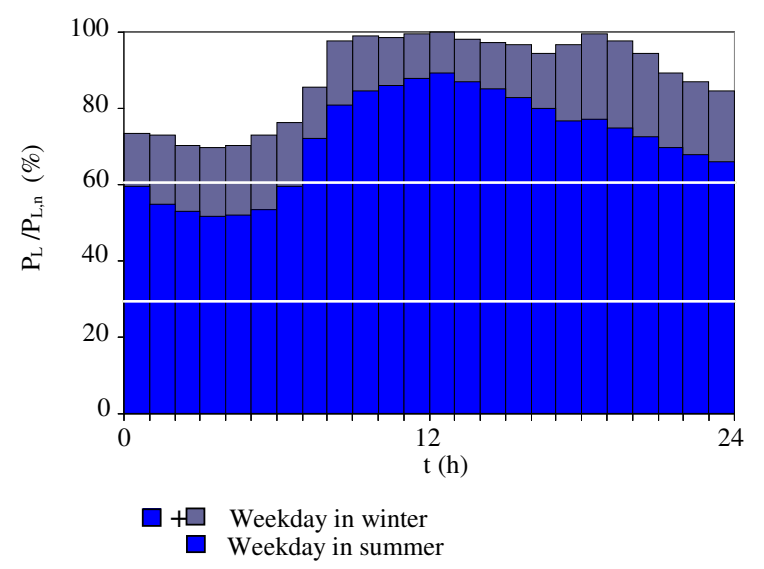

Fig. 1. Load curve and installed wind power up to the year 2020

\section{Ancillary Services}

Supporting frequency and voltage control is vital for the secure operation of an electrical grid.

\section{A. Frequency Control}

To ensure the secure operation of an electrical grid, control power is necessary for the regulation of power and frequency fluctuations. Control power $\left(\mathrm{P}_{\text {control }}\right)$ has 
two directions. The first is negative control power, which reduces the power fed into the grid. The second is positive control power, which demands power raise, e.g. extra delivery from power plants [3] (Fig. 2):

1) Primary Control: The primary control power must be fully activated not later than 30 seconds after unpermitted frequency deviation. The maximum time of delivery is 15 minutes. All participating power plants deliver primary control power and the costs are jointly shared. The participating power plants have to deliver at least +/-5 MW [4].

2) Secondary Control: The secondary control power must be fully activated not later than 900 seconds. This means that after 900 seconds the full primary control power must be replaced with secondary control power. The maximum time of delivery is 60 minutes. Secondary control must be automatically activated by the affected TSO. Suppliers have to deliver at least +/-10 MW [5].

3) Tertiary Control: The manually activated tertiary control takes place after 900 seconds up to 1 hour and is then replaced with "hour-reserve", if necessary. As before, the TSO is responsible. Suppliers have to deliver at least +/-15 MW [6].

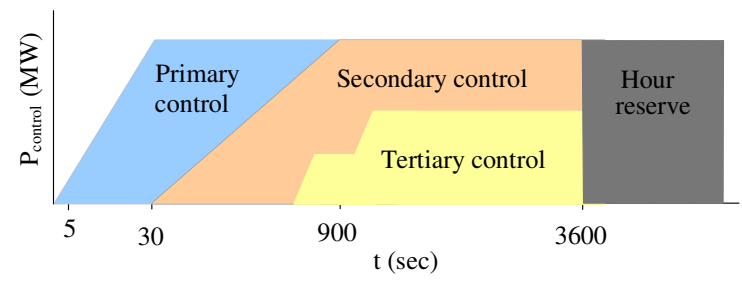

Fig. 2. Time limits of control power delivery

Wind farms should also fulfil these technical requirements if there are to participate in frequency control. Control power includes primary, secondary and tertiary control power. The transmission system operator is responsible for the organisation and feed-in of the control power. This control power should be provided by power stations. Therefore, the TSOs have to pay the power station owners the costs of providing the demanded control power for primary, secondary and tertiary control and the energy costs for delivery of the secondary and tertiary control energy. The TSO passes these costs on to the customers. This means that the customers ultimately have to pay these costs. Therefore, the TSO has to purchase the demanded control power and energy whilst keeping its costs minimal.

4) Control Power providing through Wind Power Plants:

4.1) Delivered Power of Wind Power Plants: The delivered power $(\mathrm{P})$ of a wind power plant can be calculated with (1) [7]:

$$
\begin{array}{ll} 
& \multicolumn{1}{c}{\mathrm{P}=(Л / 2) \cdot \rho \cdot \mathrm{v}_{\mathrm{w}}^{3} \cdot \mathrm{R}^{2} \cdot \mathrm{c}_{\mathrm{P}}} \\
\mathrm{v}_{\mathrm{w}} & \text { Velocity, } \mathrm{m} / \mathrm{sec} \\
\rho & \text { Air density, } \mathrm{kg} / \mathrm{m}^{3} \\
\mathrm{R} & \text { Rotor radius of a wind turbine, } \mathrm{m} \\
\mathrm{c}_{\mathrm{P}} & \text { Power coefficient }
\end{array}
$$

$c_{P}$ is dependent on the rotational speed of the blade $(\lambda)$ and pitch angle $(\beta$, angle of blades relating to their long axis):

$$
c_{P}=c_{1} \cdot\left(c_{2}-c_{3} \cdot \beta-c_{4} \cdot \beta^{X}-c_{5}\right) \cdot e^{-c_{6}(\lambda, \beta)}
$$

$\mathrm{c}_{1}-\mathrm{c}_{6}$ and $\mathrm{x}$ are coefficients, which characterise each wind turbine and can be different for various types of wind power plants. $\lambda$ can be calculated with (3) and (4). Where $\omega$ is angular speed, $\mathrm{rad} / \mathrm{sec}$

$$
\begin{gathered}
\lambda=\omega . \mathrm{R} / \mathrm{v}_{\mathrm{w}} \\
\omega=2 \text { Л. } \mathrm{R}
\end{gathered}
$$

4.2) Providing the demanded Control Power through Wind Power Plants: Fig. 3 (by $\beta_{1}$ ) shows the relation between the delivered power of a wind power plant and wind velocity. This relation is called the power curve of a wind power plant. This curve has four stages. In the first stage, the wind velocity $\left(\mathrm{v}_{\mathrm{W}}\right)$ is less than the turn on velocity $\left(\mathrm{v}_{\mathrm{W}, \mathrm{on}}\right)$; $\mathrm{v}_{\mathrm{W} \text {,on }}>\mathrm{v}_{\mathrm{W}}$. The wind power plant does not deliver any power into the grid. In the second stage $\mathrm{v}_{\mathrm{W} \text {,on }} \leq \mathrm{v}_{\mathrm{W}} \leq \mathrm{v}_{\mathrm{W}, \mathrm{n}}$, where $\mathrm{v}_{\mathrm{W}, \mathrm{n}}$ is the nominal wind velocity, the wind power plant delivers the grid with active power according Eq. 1. In the third stage $\mathrm{v}_{\mathrm{W}, \mathrm{n}}<\mathrm{v}_{\mathrm{W}}<\mathrm{v}_{\mathrm{W} \text {,off }}$, where $\mathrm{v}_{\mathrm{W} \text {,off }}$ is the turn off wind velocity, the wind power plant should be throttled through the control of pitch angle in order to protect the plant mechanically and thermally. In the fourth stage, the wind velocity is larger than the permitted wind velocity of the wind power plant ( $\left.\mathrm{v}_{\mathrm{W}} \geq \mathrm{v}_{\mathrm{W} \text {,off }}\right)$. In order to protect the wind power plant mechanically, the plant should be disconnected from the grid.

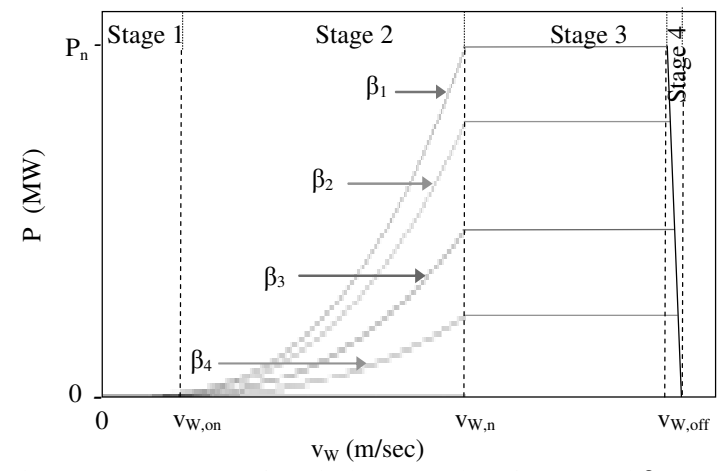

Fig. 3. Power curve of a wind power plant for several $\beta$ values

Fig. 3 also shows that the control of pitch angle enables a wind power plant to deliver the grid with different active powers in the second and third stages with the same wind velocity. E.g. to provide 
positive control power, a wind power plant should be operated with $\beta_{2}$. So the wind power plant can deliver more power into the grid, if necessary. Further throttling of $\beta$, (e.g. up to $\beta_{3}$ or $\beta_{4}$ ) enables a wind power plant to deliver less power into the grid, if necessary. Hence, wind power plants can meet the demand for positive and negative control power.

5) Contribution of Wind Power Plants to Primary Control: This study investigated if a wind power plant can fulfill the technical requirements outlined in chapter 2.A.1 to participate in primary control. In other words, whether a wind power plant can deliver the demanded primary control power not later than 30 seconds from the unpermitted frequency deviation. For this purpose two types of wind power plants were tested. These two types are the modern types of wind power plants. Modern wind power plants are equipped either with a double fed induction generator (DFIG) or a synchronous generator in combination with a full converter (SGCON).

5.1) A Wind Power Plant with a Double Fed Induction Generator: A double fed induction generator (DFIG) is an induction generator, where the rotor is connected to the grid via a converter (Fig. 4). The converter's power is approximately $30 \%$ of the generator power [8]. This type of wind power plant was simulated as in Fig. 4 and 5.

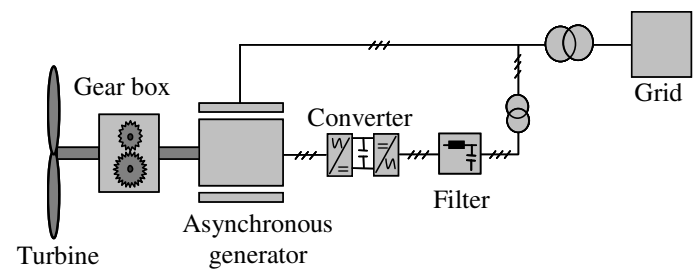

Fig. 4. A wind power plant with a DFIG

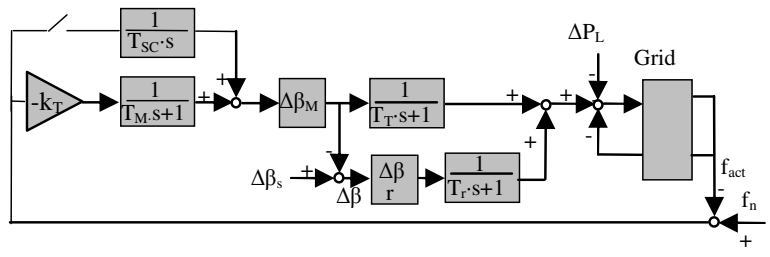

Fig. 5. Model of a wind power plant with a DFIG

Where:

f Frequency, $\mathrm{Hz}$

k Performance coefficient, $\mathrm{W} / \mathrm{Hz}$

r Rotational speed of a generator, rpm

s Laplace operator

$\mathrm{T}$ Time, sec or hour

$\mathrm{v}$ Velocity, $\mathrm{m} / \mathrm{sec}$

$\Delta$ Deviation from the observed value

For subscripts

act Actual value

L Load

\section{Motor \\ s Set value \\ $\mathrm{T}$ Turbine}

If a wind power plant with a DFIG participates in primary control, it has to change its delivered power by a frequency deviation (power unbalance). The delivered power can be changed through the control (change) of pitch angle $\beta$. The motor which controls pitch angle needs a time $T_{M}$ sec to reach the necessary torque. This motor will choose a set value for pitch angle. $\beta$ cannot be changed in small steps. If the set value of $\beta$ is not included within the possible steps provided in the look up table $\left(\Delta \beta_{\mathrm{M}}\right)$, the motor chooses the next possible given value of $\beta$. The $\beta$-changing of the blades needs $\mathrm{T}_{\mathrm{T}}$ sec.

$$
\mathrm{T}_{\mathrm{T}}=\mathrm{J} . \omega / \mathrm{P}
$$

$\mathrm{J}$ is the rotor inertia moment of the turbine. So the delivered mechanical power of the turbine into the generator would be changed. Therefore the delivered active power of the generator into the grid will also change. The deviation between the set and the chosen values of $\beta$ can be adjusted through changes to the generator slip. To evaluate the developed model, a $2 \mathrm{MW}$ wind power plant with a DFIG was simulated: nominal wind velocity $\mathrm{v}_{\mathrm{W}}=$ $\mathrm{v}_{\mathrm{W}, \mathrm{n}}=10.6 \mathrm{~m} / \mathrm{sec}, \beta$ is throttled up to $0.6^{\circ}$. Thus, delivered power of the investigated wind power plant is throttled to $95 \%$ of its nominal value, $\mathrm{P}=1.9$ MW, $\lambda=\lambda_{\mathrm{n}}=7.7 \mathrm{rpm}$, load step $\Delta \mathrm{P}_{\mathrm{L}}=0.05 \mathrm{MW}$, $\mathrm{J}=9 \cdot 10^{6} \mathrm{~kg} \cdot \mathrm{m}^{2}, \mathrm{~T}_{\mathrm{M}}=0.2 \mathrm{sec}, \mathrm{T}_{\mathrm{T}}=2.9 \mathrm{sec}$.
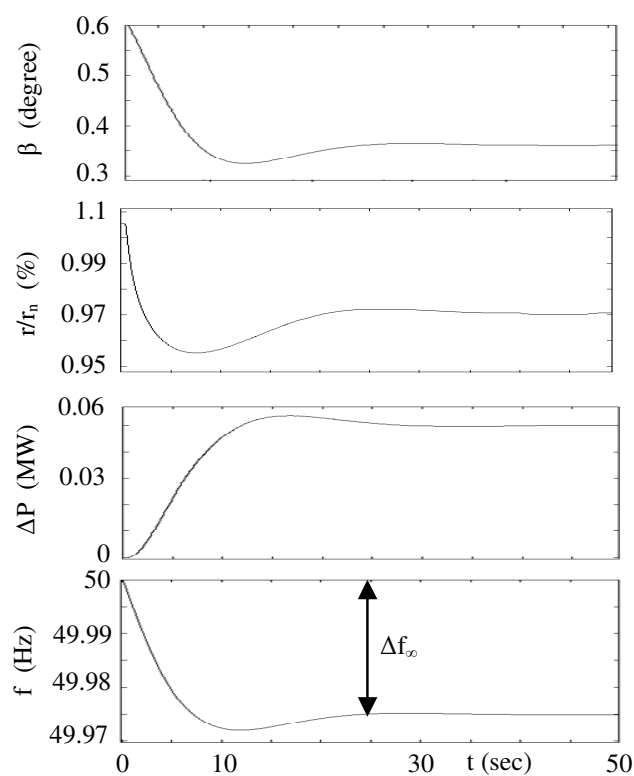

Fig. 6. Primary control with a wind power plant with a DFIG

Fig. 6 shows that with a load step larger than zero $\Delta \mathrm{P}_{\mathrm{L}}>0$ (more load), the frequency deviation is less than zero $\Delta f<0$. So the frequency is less than its nominal value $(50 \mathrm{~Hz})$. To deliver the primary control power through this wind power plant, $\beta$ and 
the slip (the rotational speed of the generator, $r$ ) were modified. The primary control power can be delivered within 15 seconds. Therefore, this wind power plant can participate in primary control. The implemented controller is a proportional controller. Thus, a static frequency deviation $\left(\Delta \mathrm{f}_{\infty}\right)$ is to be seen after activation of primary control.

5.2) A Wind Power Plant with a Synchronous Generator and Full-Converter: A synchronous generator in combination with a full-converter (SGCON) is a synchronous generator, whereby its stator is connected to the network via a converter (Fig. 7). The power of the converter is $100 \%$ of the generator power [8]. This type of wind power plant was simulated as in Fig. 7 and 8. A synchronous generator has no slip. Therefore, the model of a SGCON (Fig. 8) is simpler than the model of a DFIG (Fig. 5). Simulation results show that this type of wind power plant can also participate in primary control.

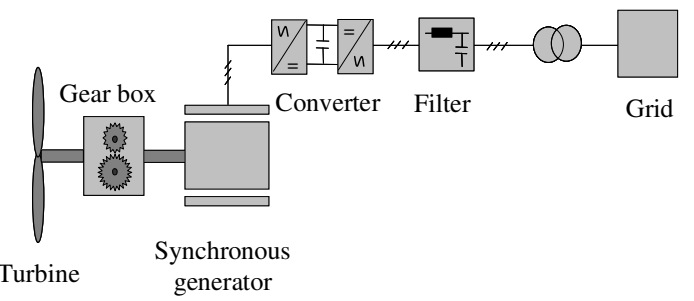

Fig. 7. A wind power plant with a SGCON

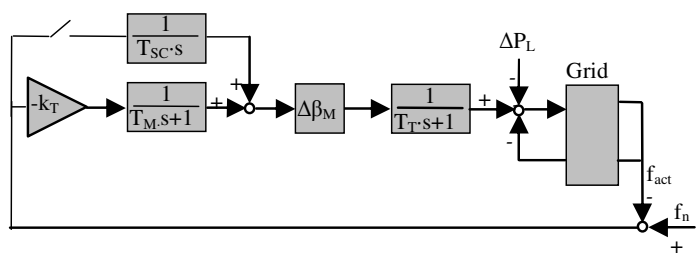

Fig. 8. Model of a wind power plant with a SGCON

6) Contribution of a Wind Power Plant to Secondary Control: Closing the switch in Fig. 5 or 8 should enable a wind power plant with a DFIG or with a SGCON to participate in secondary control as well. The same wind power plants as in chapter 2.A.5.1 were investigated. Fig. 10 shows that the participation of a wind power plant equipped with DFIG or SGCON in secondary control leads to an adjustment of the frequency to its nominal value within 900 seconds. So, these types of wind power plants can participate in secondary control. The used controller is a proportional-integral controller.

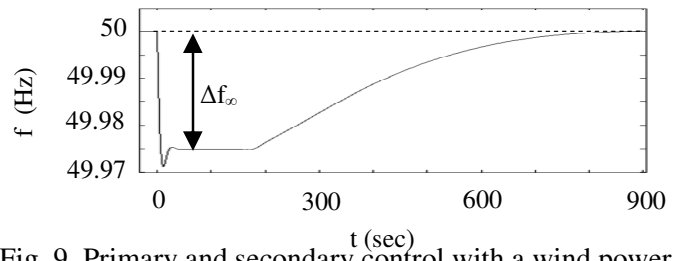

Fig. 9. Primary and secondary control with a wind power plant equipped with a DFIG or with a SGCON
7) Contribution of a Wind Farm to Primary and Secondary Control: Wind power plants are connected to the grid in wind farms. Therefore, it is essential to investigate the extent to which a wind farm can participate in primary and secondary control.

7.1) A Wind Farm with a Double Fed Induction Generator: The model of a wind power plant implemented with a DFIG in Fig. 5 was advanced for a wind farm. The investigated wind farm has three wind power plants. Two of them have to participate in primary control (wind power plants 1 and 2). The other wind power plant (wind power plant 3) has to participate in primary and secondary control. At nominal wind velocity, all wind power plants were throttled. So each wind power plant delivers 1.9 MW instead of $2 \mathrm{MW}$. The load step is $0.1 \mathrm{MW}$. At a power unbalance, Fig. 10 shows that firstly all wind power plants deliver the demanded primary control power within the permitted time (30 seconds). So this wind farm can participate in primary control. After about 200 seconds, the secondary control would be activated. The wind power plant number 3 delivers the demanded secondary control power within 900 seconds (15 minutes). The secondary control replaces the primary control. The frequency would be adjusted to its nominal value. Thus, this wind farm can participate in primary and secondary control.

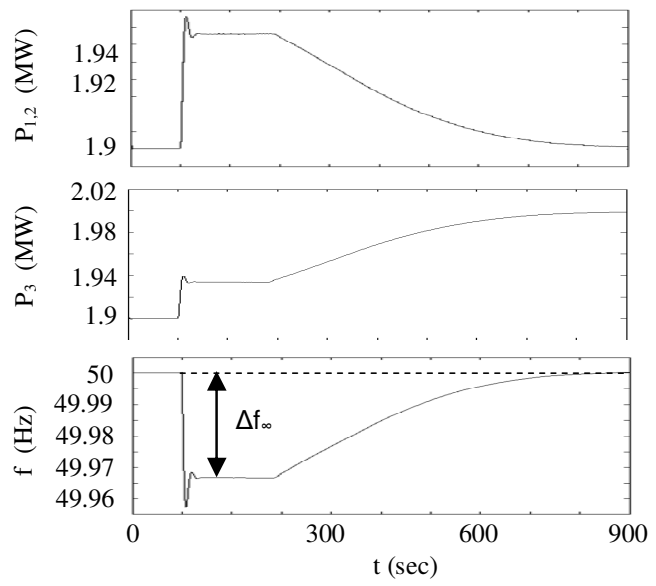

Fig. 10. Primary and secondary control with a wind farm implemented with DFIG

7.2) A Wind Farm with Synchronous Generator and Full-Converter: The same result will be achieved if the wind farm is equipped with a SGCON.

In all studies of this work the frequency was used as a controlled variable. Each wind farm which participates in primary control should have frequency measuring equipment at the wind farm directly. With secondary control, there is only one piece of frequency measuring equipment at the grid control centre. The grid was simulated through the load and the rotating masse. 
8) Contribution of Wind Power Plants to Tertiary Control: The tertiary control power has to be activated manually. As illustrated in chapter 2.A.4.2, the delivered power of a wind power plant or a wind farm can be controlled manually through manual control of the pitch angle. Therefore, wind power plants can participate in tertiary control.

Thus, a wind power plant or a wind farm can participate in frequency control; primary, secondary and tertiary control simultaneously.

9) Possible Control Power provided by Wind Power Plants: the demanded power of primary and secondary control is to be announced for one month ahead. Every bidder must be able to provide his part of control power for one month. Wind velocity and thus the delivered power from wind power plants cannot be predicted for one month ahead. Due to this, wind power plants may not offer a bid to participate in frequency control. So in this study, it is assumed that the demanded power of primary and secondary control is to be announced for the next 24 hours, like the demanded power of tertiary control. The wind velocities of the observed day should be predicted. The delivered power from a wind power plant concerning the predicted wind velocities should be calculated as in (1). The difference between the minimal delivered power of a wind power plant on the observed day $\left(\mathrm{P}_{\mathrm{d}}\right)$ and the possible minimal delivered power of the observed wind power plant $\left(\mathrm{P}_{\mathrm{m}}\right)$ is the possible control power provided (Fig. 11). If there is no wind for one or more periods on the observed day, the wind power plants may not contribute to the support of frequency control. In order to provide the minimum power of primary control $(+/-5 \mathrm{MW})$, secondary control (+/-10 MW) or tertiary control (+/-15 MW), wind power plants may join together to offer a shared bid to contribute to frequency control.

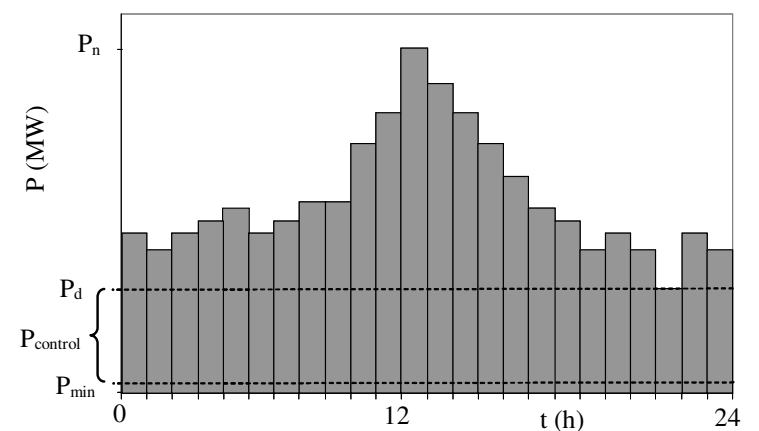

Fig. 11. Possible provided control power through a wind power

\section{B. Voltage Control}

The voltage of an electrical grid must be kept within the permitted range. Reactive power is necessary to support the voltage control. Up until now, this reactive power has had to be delivered from conventional power plants and reactive power compensation equipment. Wind farms supply the grid with active power only, and therefore they farms have not participated in voltage control up to now. If wind farms are to participate in voltage control, they have to be able to supply reactive power into the grid.

As mentioned above, modern wind power plants are equipped either with DFIG or SCCON. These two types of wind power plants were simulated to investigate how far these types can support voltage control. Simulations results show that both of these types can supply reactive power into the grid. Fig. 12 shows the PQ curve of a DFIG. The simulated DFIG is the same as in chapter 2.A.5.1. A part of the generated energy of a wind power plant will be supplied to the grid via converter. The angle between the delivered current and voltage through this converter can be adjusted as desired. A wind power plant can therefore supply inductive and capacitive reactive power into the grid to support voltage control at the connection node. Inductive reactive power can be supplied to reduce the voltage at the connection node and the capacitive reactive power can be supplied for voltage raising.

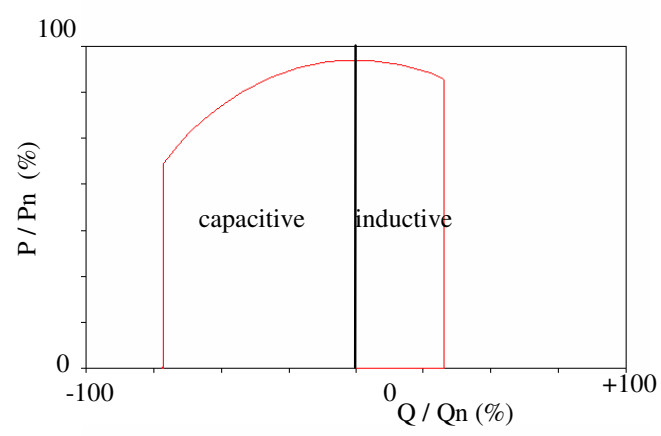

Fig. 12. Possible supplied reactive power of a DFIG

\section{Economical Benefits of Contribution of Wind Power Plants to Frequency Control}

In this study, the participation of wind power plants to frequency control is economically evaluated. The test model consists of a $380 \mathrm{kV}$ and two subordinate $110 \mathrm{kV}$ grids. The wind power plants are connected in 12 wind farms to the $110 \mathrm{kV}$-grids. Total load of the grid is $4.2 \mathrm{GW}$. The installed wind power is equal to $25 \%$ of the total load.

Table 1 shows bid prices for providing and delivering the demanded positive and negative control power and energy of primary control $\left(\mathrm{PC}^{-}, \mathrm{PC}^{+}\right)$, secondary control $\left(\mathrm{SC}^{-}, \mathrm{SC}^{+}\right)$and tertiary control $\left(\mathrm{TC}^{-}, \mathrm{TC}^{+}\right)$of conventional power plants (CPP) in high (HT) and low tariff (LT) for an exemplary day. In the table + is for positive and - for negative control power. HT should be paid from 08:00 to 20:00 on a weekday, otherwise the delivered control energy should be paid at low tariff. Table 1 also provides the price that the wind power plants (WPP) have to bid to participate in frequency control. 
Table 1. Bid Price For Participation in Frequency Control

\begin{tabular}{|c|c|c|c|c|c|c|c|}
\hline \multicolumn{2}{|c|}{} & \multicolumn{2}{|c|}{$\begin{array}{c}\text { Power costs } \\
(€ / M W / D a y)\end{array}$} & \multicolumn{4}{|c|}{$\begin{array}{c}\text { Energy costs } \\
(€ / M W h / D a y)\end{array}$} \\
\cline { 2 - 8 } \multicolumn{2}{|c|}{} & CPP & WPP & \multicolumn{2}{|c|}{ CPP } & \multicolumn{2}{|c|}{ WPP } \\
\cline { 3 - 8 } \multicolumn{2}{c|}{} & & & HT & LT & HT & LT \\
\hline \multirow{2}{*}{ PC } & PC $^{-}$ & 385 & 384 & - & - & - & - \\
\cline { 2 - 8 } & PC $^{+}$ & 385 & 2088 & - & - & - & - \\
\hline \multirow{2}{*}{ SC } & SC $^{-}$ & 140 & 139 & 3 & 15 & 2 & 14 \\
\cline { 2 - 8 } & SC $^{+}$ & 270 & 2088 & 140 & 70 & 139 & 69 \\
\hline \multirow{2}{*}{ TC } & $\mathrm{TC}^{-}$ & 90 & 89 & 0 & 0 & 0 & 0 \\
\cline { 2 - 8 } & $\mathrm{TC}^{+}$ & 90 & 2088 & 100 & 20 & 99 & 19 \\
\hline
\end{tabular}

Participation of wind power plants in providing positive and negative control power are investigated separately. Participation of wind power plants in providing positive control power means that the wind power plants should be throttled permanently. Thus, the wind power plant owner loses his revenues [the fixed payment based on EEG (EEG payment)] for the complete participation period (one day) for the energy not supplied into the network. Therefore, the costs of providing the positive control power through wind power plants are very high. Hence, the transmission system operator (TSO) will not buy the control power from wind power plants. Participation of wind power plants in providing the negative control power means that wind power plants are to be throttled by delivery of the negative control power only, which is delivered rarely. Thus, if the negative control power is not delivered in the observed day, the wind power plant owner receives the EEG payment as well as the costs of providing the demanded negative control power (primary, secondary and tertiary control, $612 € / \mathrm{MW} /$ day)

If wind power plants contribute for one year to providing the demanded negative control power (primary, secondary and tertiary control), the wind power plant owner receives more income $(10.8 \%$ more $)$ than the income based on the EEG payment (for 40 deliveries/year of the negative control power). In this study the total income of the wind power plant owner with and without participation in supporting the frequency control may not be changed. Therefore, increased income through the participation of wind power plants in supporting frequency control leads to a reduction in the EEG fixed payment. Thus, the EEG payment can be reduced from 87 to $77.6 € / \mathrm{MWh}$ in the observed year. The major reduction can be obtained through the participation of wind power plants in providing the negative primary control power (Fig. 13). For various numbers of deliveries of negative control power per year, Table 2 shows that the contribution of the wind power plants to providing the negative control power to support frequency control also leads to a reduction in the EEG payment.

Table 2. Possible Reduction of the EEG payment for various numbers of delivery per year

\begin{tabular}{|c|c|}
\hline $\begin{array}{c}\text { Number of } \\
\text { deliveries/year }\end{array}$ & $\begin{array}{c}\text { Possible reduction of } \\
\text { EEG payment }(\%)\end{array}$ \\
\hline 0 & 10.9 \\
\hline 40 & 10.8 \\
\hline 80 & 10.7 \\
\hline
\end{tabular}

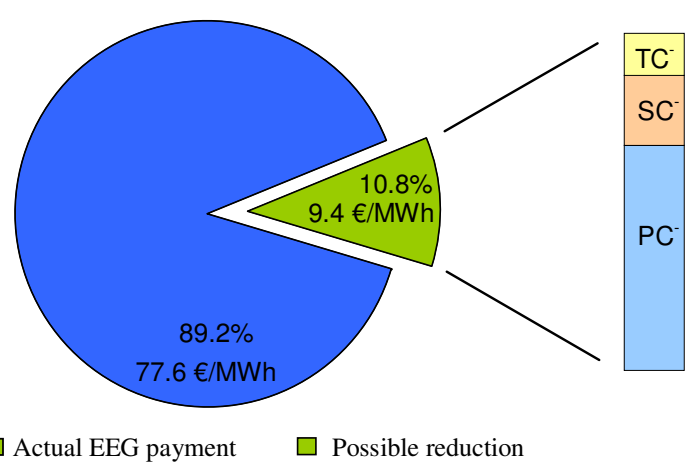

Fig. 13. Possible reduction of the EEG payment in the observed year

\section{Conclusion}

A wind power plant or a wind farm can support voltage and frequency control. They can fulfil the technical requirements to participate in primary, secondary and tertiary control. Participation of wind power plants in providing the demanded negative control power enables the wind power plant owners to receive more income than the income based on the EEG payment. This extra income can contribute to a reduction in the EEG payment, where wind power plant owners should get the same income with and without participation in frequency control support. Thus, the TSO and customers pay less for the energy generated by wind power plants.

\section{References}

[1] Planning of the Grid Integration of Wind Energy in Germany Onshore and Offshore up to the Year 2020 (dena Grid Study). German Energy Agency. Berlin, 2005

[2] Act Revising the Legislation on Renewable Energy Sources in the Electricity Sector and Amending Related Provisions (Renewable Energy Sources Act). Federal Ministry for Environment, Nature Conservation and Nuclear Safety. Federal Law Gazette I. No. 49. Bonn, 2008

[3] Transmission Code 2007 - Network and System Rules of the German Transmission System Operators. Berlin, 2007

[4] Verfahren zur Ausschreibung von Regelenergie in Gestalt der Primärregelleistung. Federal Network Agency. Ruling Chamber 6. No. 6-06-065. Bonn, 2007

[5] Verfahren zur Ausschreibung von Regelenergie in Gestalt der Sekundärregelleistung. Federal Network Agency. Ruling Chamber 6. No. 6-06-066. Bonn, 2007

[6] Festlegung der Minutenreserve. Federal Network Agency. Ruling Chamber 6. No. 6-06-012. Bonn, 2006

[7] A. Lebioda, K. Rudion, Z. Styczynski. Investigation of Disposable Reserve Power in a Large-Scale Wind Farm. IEEE Power Tech Conference. St. Retersburg. Russia. 2005, pp 724

[8] A-R. Al-Awaad, J. Verstege. PQ-Curve of Wind Power Plants. European EMTP-ATP Conference. Leòn. Spain. 2007, pp A1 